\title{
Estructura de bosques con palo santo (Gonopterodendron sarmientoi): Evaluación regional para su manejo y conservación en la Argentina
}

\author{
Dante Loto ${ }^{1, \bigotimes}$; Sebastián Kees²; Maximiliano Azcona 3 ; Santiago De Tellería ${ }^{3} ;$ \\ Eduardo Manghi ${ }^{3}$; Juan Gaitán ${ }^{4}$; Carlos Spagarino ${ }^{5}$; Ignacio Gasparri ${ }^{6}$ \& Pablo \\ PERI $^{7}$
}

${ }^{1}$ Instituto de Silvicultura y Manejo de Bosque Nativos (INSIMA). Universidad Nacional de Santiago del Estero (UNSE). Consejo Nacional de Investigaciones Científicas y Técnicas (CONICET). Santiago del Estero, Argentina. ${ }^{2}$ Campo Anexo Estación Forestal Plaza - Estación Experimental Agropecuaria (EEA) Sáenz Peña. Instituto Nacional de Tecnología Agropecuaria (INTA). Chaco, Argentina. ${ }^{3}$ Dirección Nacional de Bosques (Autoridad Científica CITES en especies forestales). Ministerio de Ambiente y Desarrollo Sustentable de la Nación (DNB, MAyDS). Argentina. ${ }^{4}$ INTA. Buenos Aires, Argentina. ${ }^{5}$ Parque Nacional Río Pilcomayo. Administración de Parques Nacionales (APN). Formosa, Argentina. ${ }^{6}$ Instituto de Ecología Regional. CONICET. Universidad Nacional de Tucumán (UNT). Tucumán, Argentina. ${ }^{7}$ EEA Santa Cruz, INTA. Universidad Nacional de la Patagonia Austral (UNPA). CONICET. Santa Cruz, Argentina.

\begin{abstract}
Resumen. Gonopterodendron sarmientoi es un árbol nativo de los bosques del Gran Chaco Seco de Sudamérica, adaptado a condiciones semiáridas. Hasta el momento no se ha relacionado la estructura forestal de palo santo con características edáficas y climáticas a escala regional. Actualmente, en la Argentina, el estudio del manejo y la conservación forestal de esta especie es escaso y aún depende de la disponibilidad de información básica. Los objetivos del presente trabajo fueron: 1) clasificar estructuras de bosques de palo santo según el índice de valor forestal y la composición de especies, 2) analizar relaciones entre parámetros dasométricos de palo santo con variables edáficas y climáticas a nivel región y tipos de bosques, y 3) comparar la biomasa total aérea entre los tipos de bosques como herramienta para el manejo y la conservación de la especie. Se recopilaron inventarios forestales realizados durante los años 2004-2019 conteniendo datos dasométricos de palo santo para el norte del Chaco Seco argentino. Dentro del área de estudio se extrajeron registros edáficos y climáticos de las unidades de muestreo a partir de bases de datos globales y de mapas nacionales. Se determinaron tres tipos de estructuras de bosques con presencia de palo santo: palosantal, bosque con baja presencia de palo santo y bosque con alta presencia de palo santo. La temperatura, la precipitación, la evapotranspiración y las texturas del suelo tuvieron efectos significativos sobre la estructura forestal del palo santo a nivel de región y sobre los tipos de bosques. La densidad total de individuos de G. sarmientoi tiene diferente efecto sobre la biomasa total según el tipo de bosque, lo que posibilita diferentes prácticas de manejo y conservación. Consolidar un Plan Estratégico Nacional para el Manejo Sustentable del Palo Santo en la República Argentina podría atender más propuestas viables de manejo y conservación de la especie en la región.
\end{abstract}

[Palabras clave: palosantal, área basal, altura, tipos de bosques, suelo, clima, biomasa, recurso forestal, Chaco Seco]

\begin{abstract}
Aвstract. Forests structure of palo santo (Gonopterodendron sarmientoi): Regional assessment for forest management and conservation in Argentine. Gonopterodendron sarmientoi is a threatened native tree of the Dry Chaco region in South America, adapted to semiarid conditions. However, the relationships among climatic and edaphic conditions and its forest structure have not been defined yet. Up to date, in Argentina, the study of palo santo forest management and conservation is scarce and still depends on basic information. The objectives of this study were 1) to classify forest groups based on forest stand attributes and species composition, 2) to analyze relationships between dasometric parameters of palo santo with climatic and edaphic variables at the regional level and forest types, and 3) to compare total aboveground biomass between forest types as a tool for managing and conserving this species. We compiled forest inventories carried out during the years 2004-2019, containing dasometric data of palo santo for the northern part of the Argentine Dry Chaco region. In the study area, we extracted climatic and edaphic conditions from global data base and national maps. We obtained three forest groups: palosantal, forests with low presence of palo santo and forests with high presence of palo santo. Temperature, precipitation, evapotranspiration and soil textures had significant effects on the forest structure of palo santo at the regional level and on forest types. The total density of individuals of $G$. sarmientoi has a different effect on the total biomass depending on the type of forest, which allows for different management and conservation practices. Consolidating a national forest plan for palo santo could address more viable proposals to manage and conserve the species in the region.
\end{abstract}

[Keywords: palosantal, basal area, height, forest types, soil, climate, biomass, forest resource, Dry Chaco]

Editor asociado: Guillermo Martínez Pastur

$\bar{\triangle}$ danteloto87@gmail.com
Recibido: 18 de Junio de 2021

Aceptado: 18 de Agosto de 2021 


\section{INTRODUCCIÓN}

El palo santo, Gonopterodendron sarmientoi (Lorentz ex Griseb.) A. C. Godoy-Bürki (Zygophyllaceae) es un árbol endémico del sur de Sudamérica. Se distribuye en la región del Gran Chaco Seco, incluyendo el norte de la Argentina, el este de Bolivia y el oeste de Paraguay (Mereles and Pérez de Molas 2008; Barstow 2018). Gonopterodendron sarmientoi es una especie forestal de madera dura (Giménez and Moglia 2003) utilizada principalmente en pisos y postes debido a su alta durabilidad, en diversos productos de tornería y tallados, y para obtener aceites esenciales (Céspedes et al. 2018). En las últimas décadas, este recurso maderero también logró un reconocimiento en el mercado internacional, con un gran volumen de madera demandada (Mereles and Pérez de Molas 2008; CITES 2010; Céspedes et al. 2018). El Comercio Internacional de Especies Amenazadas de Fauna y Flora Silvestre (CITES) recategorizó a esta especie en la Argentina dentro del Apéndice II (mayor amenaza). Esto habilita permisos de exportación internacional con previa concesión del organismo regulador para demostrar que no se afecta su supervivencia (Ley 22344). Sin embargo, hasta el momento, el manejo y la conservación de este recurso ha sido poco estudiado. Además, dentro del área de distribución del palo santo en la Argentina es usual que se reporten aprovechamientos no planificados, extracción de tipo minera y degradación de rodales (Waller 2009; Loto et al. 2018).

Los modelos de distribución de especies en función de variables bioclimáticas y edáficas han demostrado patrones significativos en la delimitación del nicho ecológico para muchas especies dominantes de árboles en la región del Chaco Seco argentino (Morello and Adamoli 1974; Torres et al. 2014; Powell et al. 2018). Gonopterodendron sarmientoi tiene un óptimo adaptativo en condiciones ambientales áridas y semiáridas de bosques secos en el sur de Sudamérica (Camps et al. 2018). Sin embargo, las principales variables climáticas y edáficas limitantes para estos bosques han sido poco analizadas. Los rasgos morfológicos de las hojas y el leño sugieren que G. sarmientoi responde a procesos ambientales siguiendo una dinámica de centro-periferia, en la que los centros son áreas geográficas con condiciones ambientales más estables y favorables para un mejor desempeño de la especie, condiciones que disminuyen hacia zonas geográficas periféricas (Camps et al. 2021).
Gonopterodendron sarmientoi tendría buen desempeño poblacional en áreas centrales de climas áridos y semiáridos, mientras que en climas periféricos subhúmedos habría poblaciones de pocos individuos con rasgos morfológicos diferenciados (Camps et al. 2021). Esto podría indicar cambios en las estructuras forestales de palo santo a lo largo de un gradiente climático y edáfico. Hasta el momento, dichos bosques sólo fueron caracterizados para sitios puntuales en el norte de la Argentina (Morello and Adamoli 1974; Waller 2009; Loto et al. 2018). Por esta razón, a escala regional, en nuestro país aún se conoce poco la relación entre la estructura forestal de palo santo con un gradiente climático y edáfico.

Conocer los aspectos básicos de la estructura y la dinámica forestal del bosque es un paso necesario para planificar el manejo de los recursos forestales. La estructura forestal, definida por la distribución vertical y horizontal de árboles en una superficie determinada, permite evaluar los impactos y la recuperación potencial del recurso forestal (Lamprecht 1990). Los bosques con presencia de palo santo fueron descritos como un tipo de vegetación arbórea inundable dentro de la ecorregión del Chaco Seco (Morello and Adamoli 1974). Sin embargo, los bosques chaqueños no inundables con presencia de esta especie tienen una gran diversidad de estructuras forestales (Waller 2009; Gómez et al. 2013; Loto et al. 2018). Hasta el presente, los datos de inventarios locales (Waller 2009; Loto et al. 2018) y regionales (SAyDS 2014; MAyDS 2020) coinciden en que: a) G. sarmientoi es una de las especies que define la estructura del bosque, b) su distribución espacial sigue patrones geomorfológicos (i.e., suelos), y c) existen signos de aprovechamientos no planificados de la especie.

Una gran proporción de bosques chaqueños en la Argentina son propensos a disturbios y aprovechamientos que conducen a una degradación de los recursos madereros de la región (De Marzo et al. 2021). Los bosques de palo santo en la Argentina no están exentos del uso forestal (Waller 2009; Loto et al. 2018), además de que no se dispone de una evaluación detallada de sus estructuras forestales en relación con la capacidad productiva a fin de planificar el manejo y la conservación. En este contexto, los objetivos del presente trabajo fueron: 1) clasificar tipologías de bosques con palo santo en base a parámetros de estructura forestal y composición de especies, 2) analizar 
relaciones entre la estructura forestal del palo santo con variables climáticas y edáficas a nivel región y tipos de bosques, y 3) comparar la biomasa total aérea entre los tipos de bosques de palo santo como herramienta para manejar y conservar la especie en la región.

\section{Materiales y Métodos}

\section{Área de estudio}

El área de estudio se encuentra ubicada en el norte de la Argentina (Figuras 1A y 1B), dentro del dominio fitogeográfico regional del Chaco Seco (Cabrera 1976), incluyendo el oeste de las provincias de Chaco y Formosa, y el este de la provincia de Salta $\left(22.0^{\circ}-25.8^{\circ} \mathrm{S}, 59.3^{\circ}-64.6^{\circ}\right.$ O). La vegetación es xerófila, con mosaicos de bosques, pastizales, sabanas y arbustales como unidades predominantes en el paisaje (Morello and Adamoli 1974). Las especies arbóreas más frecuentes son Aspidosperma quebrachoblanco, Schinopsis lorentzii y Gonopterodendron sarmientoi, que pueden alcanzar hasta $20 \mathrm{~m}$ de altura (Cabrera 1976). En el estrato superior también pueden participar especies como Sarcomphalus mistol, Prosopis nigra y Prosopis alba. Por debajo del dosel superior se pueden encontrar a Bougainvillea praecox, Salta triflora y algunas especies de Celtis y Capparaceas (Cabrera 1976). Estos bosques chaqueños se distribuyen principalmente sobre un terreno plano con pendiente poco marcada.

\section{Estructura forestal de palo santo}

Se utilizó información recopilada a partir de inventarios forestales realizados para diferentes años en el norte de la Argentina (Tabla1). Estos inventarios forestales provienen de muestreos realizados en bosques nativos bajo la tenencia de comunidades aborígenes y campesinas, y en planes de manejo. El área de estudio cubrió las provincias de Salta, Formosa y Chaco (Figura 1B, Tabla 1). En total, se obtuvieron 482 parcelas con presencia de $G$. sarmientoi (Figura 1B). Las parcelas tuvieron forma circular, con una superficie de $1000 \mathrm{~m}^{2}$; en ellas se midieron todas las plantas leñosas $>10 \mathrm{~cm}$ de diámetro a la altura del pecho (DAP). Dentro de cada parcela se establecieron subparcelas de superficies variables $(100,200$ y $\left.500 \mathrm{~m}^{2}\right)$, donde se midieron todas las plantas leñosas entre 5-10 cm de DAP. Para medir la

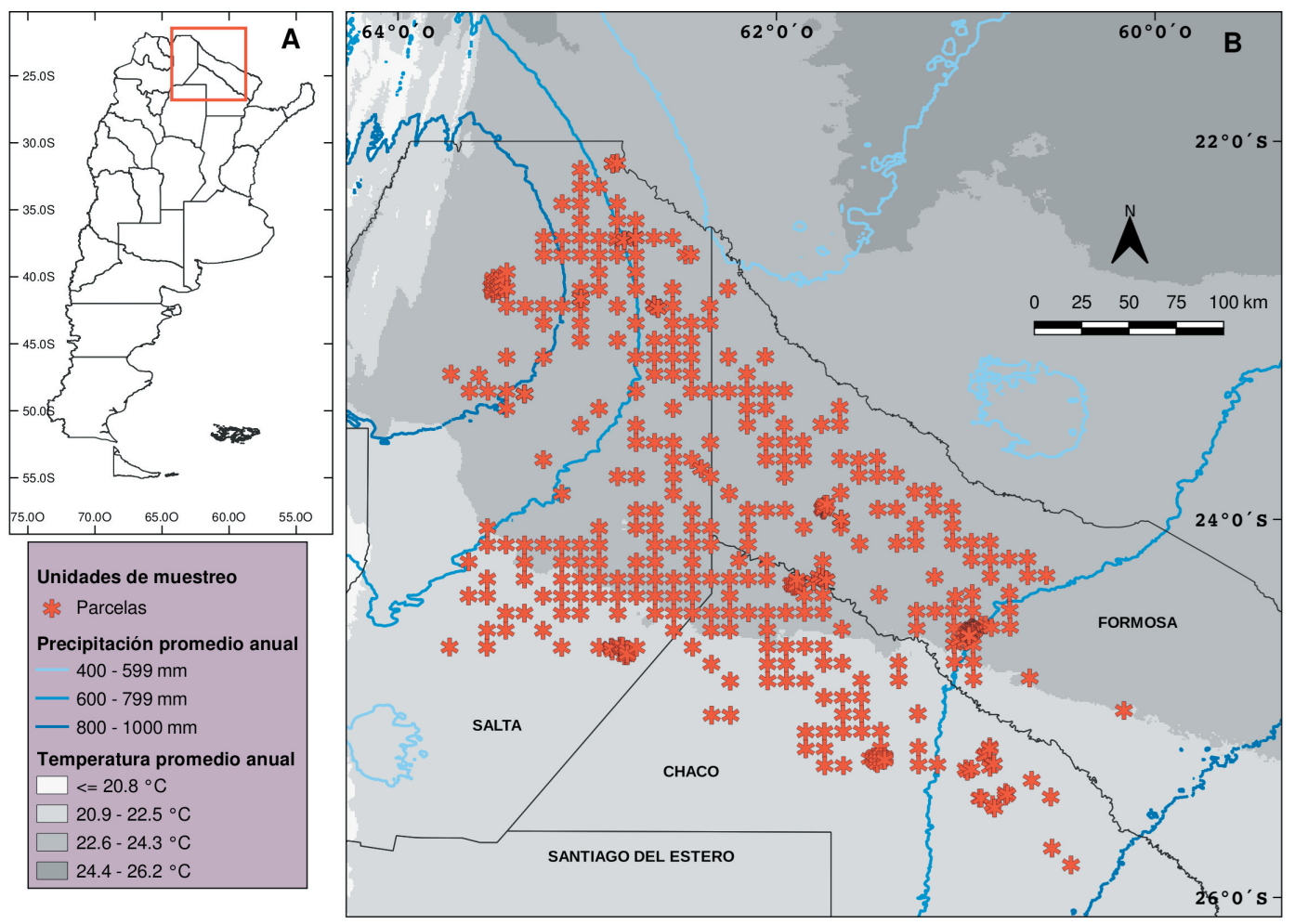

Figura 1. (A) Área de estudio en las provincias de Chaco, Formosa y Salta (Argentina). (B) Detalle de la distribución de parcelas forestales con presencia de Gonopterodendron sarmientoi en bosques del Chaco Seco argentino.

Figure 1. (A) Forest inventory in Argentina. (B) Detail of the distribution of forest plots including Gonopterodendron sarmientoi in forests of the Argentinean Dry Chaco. 
Tabla 1. Detalle de inventarios y registros forestales recopilados en el área de distribución de Gonopterodendron sarmientoi en el norte de la Argentina.

Table 1. Details of forest inventory and data compilation in the distribution area of Gonopterodendron sarmientoi in northern Argentina.

\begin{tabular}{|c|c|c|c|c|}
\hline Origen de datos & $\begin{array}{c}\text { Año de } \\
\text { muestreo }\end{array}$ & $\begin{array}{l}\text { Número de } \\
\text { unidades }\end{array}$ & Variables consideradas & Provincia \\
\hline $\begin{array}{l}\text { Inventario Forestal Comunidad } \\
\text { Wichí Lote } 27\end{array}$ & 2004 & 37 & $\begin{array}{l}\text { Diámetro normal; Altura total; } \\
\text { Altura de fuste; Regeneración }\end{array}$ & Formosa \\
\hline $\begin{array}{l}\text { Inventario Forestal Loto et al. } \\
2018\end{array}$ & 2007 & 55 & $\begin{array}{l}\text { Diámetro normal; Altura total; } \\
\text { Altura de fuste }\end{array}$ & Formosa, Salta \\
\hline $\begin{array}{l}\text { Inventario Forestal EEA - INTA. } \\
\text { Ing. Juárez }{ }^{2}\end{array}$ & 2013 & 11 & $\begin{array}{l}\text { Diámetro normal; Altura total; } \\
\text { Altura de fuste }\end{array}$ & Formosa \\
\hline $\begin{array}{l}1^{\text {er }} \text { Inventario Nacional de Palo } \\
\text { Santo. MAyDS }\end{array}$ & 2014 & 8 & $\begin{array}{l}\text { Diámetro normal; Altura total; } \\
\text { Altura de fuste }\end{array}$ & $\begin{array}{c}\text { Salta, Formosa, } \\
\text { Chaco }\end{array}$ \\
\hline $\begin{array}{l}\text { Inventarios Forestales de Planes } \\
\text { de Manejo }\end{array}$ & 2018 & 42 & $\begin{array}{l}\text { Diámetro normal; Altura } \\
\text { total;Altura de fuste }\end{array}$ & Salta, Chaco \\
\hline $\begin{array}{l}\text { Inventario Forestal PIC “Los } \\
\text { Labradores". PBNyC, MAyDS }\end{array}$ & 2018 & 41 & $\begin{array}{l}\text { Diámetro normal; Altura } \\
\text { total;Altura de fuste }\end{array}$ & Chaco \\
\hline $\begin{array}{l}2^{\mathrm{do}} \text { Inventario Nacional de } \\
\text { Bosque Nativo. MAyDS }\end{array}$ & 2019 & 288 & $\begin{array}{l}\text { Diámetro normal; Altura total; } \\
\text { Altura de fuste; Regeneración }\end{array}$ & $\begin{array}{c}\text { Salta, Formosa, } \\
\text { Chaco }\end{array}$ \\
\hline
\end{tabular}

regeneración se consideraron las plantas leñosas $<5 \mathrm{~cm}$ de DAP o plantas con altura mayor a $1.5 \mathrm{~m}$. Estas últimas fueron medidas en 90 subparcelas de menor tamaño con superficie variable $\left(25\right.$ y $\left.50 \mathrm{~m}^{2}\right)$. Se registró el DAP, la altura total y la longitud o la altura del fuste de todos los individuos a nivel de especie. Para el cálculo de volumen del fuste por individuo se empleó la fórmula de Cotta (Thren 1993). Esta ecuación utiliza un coeficiente mórfico, o factor de forma, que relaciona el volumen aproximado del fuste con el volumen de un cuerpo geométrico (e.g., cilíndrico o cónico) con la misma sección del DAP y altura de fuste (Thren 1993).

Volumen del fuste $\left(\mathrm{m}^{3}\right)=$ área basal $\left(\mathrm{m}^{2}\right) \times$ longitud del fuste $(\mathrm{m}) \times 0.7$

(Ecuación 1)

donde el volumen del fuste es igual al área basal por la longitud del fuste por el coeficiente mórfico (0.7) de cada árbol de $G$. sarmientoi. La biomasa aérea leñosa de cada árbol de palo santo se estimó con la ecuación alométrica desarrollada para bosques secos (Chave et al. 2005).

Biomasa leñosa $(\mathrm{kg})=\exp (-2.187+0.916 \times \ln [\sigma \times x$
DAP $\left.\left.{ }^{2} \times \mathrm{H}\right]\right)$
(Ecuación 2$)$

La Ecuación 2 utiliza el DAP (en centímetros), la altura total $\mathrm{H}$ (en metros) y la densidad específica $(\sigma)$ de la madera $\left(\mathrm{en} \mathrm{g} / \mathrm{cm}^{3}\right)$ de todos los árboles de palo santo. La densidad específica de madera de palo santo utilizada fue $1.15 \mathrm{~g} / \mathrm{cm}^{3}$ (Giménez and Moglia 2003). Con la Ecuación 2 se modela la cantidad de biomasa posible acumulada en función del tamaño real de cada árbol de palo santo con un error de estimación de $\pm 20 \%$ (Chave et al. 2005).

A partir de estas mediciones por individuo se calcularon las variables dasométricas totales sólo para G. sarmientoi. Se extrapoló el área basal total $\left(\mathrm{m}^{2} / \mathrm{ha}\right)$, la densidad total de individuos (individuos/ha), el volumen total del fuste $\left(\mathrm{m}^{3} / \mathrm{ha}\right)$, la altura media dominante (m) y la biomasa total (Mg/ha). Las cantidades por hectárea se obtuvieron mediante el factor de expansión, considerando el DAP de cada árbol de palo santo según la superficie de la parcela. La altura media dominante fue calculada como el promedio de los 3 árboles de palo santo con mayor altura en cada parcela.

\section{Clasificación de bosques con palo santo}

Se calculó un índice de valor por especie (IV) en cada una de las parcelas (Lamprecht 1990; Kershaw et al. 2017). Este índice se elaboró a través de la sumatoria de los valores relativos de área basal, la densidad de individuos, el volumen del fuste y la altura de cada especie por parcela. Para estimar el volumen del fuste 
de las restantes especies se aplicó la fórmula de Cotta (Ecuación 1).

De esta manera, el cálculo del IV se resume como:

$$
\mathrm{IV}_{\mathrm{ij}}=\mathrm{AB}_{\mathrm{ij}}+\mathrm{D}_{\mathrm{ij}}+\mathrm{VOL}_{\mathrm{ij}}+\mathrm{H}_{\mathrm{ij}}
$$

donde, $\mathrm{AB}$ es el área basal relativa, $\mathrm{D}$ es la densidad relativa de individuos, VOL es el volumen del fuste relativo y $\mathrm{H}$ es la altura relativa. Esta última variable se calculó como el cociente entre la altura promedio de cada especie y la altura media dominante de la parcela (considerando los tres árboles más altos de la parcela). Todos estos parámetros fueron referidos a la i-ésima especie dentro de la j-ésima parcela del inventario forestal. Así se obtuvo una matriz con los valores IV, en la que las filas corresponden a cada una de las parcelas y las columnas son todas las especies presentes. El índice IV es algo diferente al índice de valor de importancia (IVI) (Lamprecht 1990). Los valores de IV son relativos e intentan representar los diferentes aportes delas especies a la estructura horizontal y vertical de cada parcela, mientras que el IVI convencional indica la estructura horizontal (Lamprecht 1990; Kershaw et al. 2017).

Con la matriz de valores IV se realizó una clasificación jerárquica multivariada para agrupar las parcelas y diferenciar grupos o tipos de estructuras forestales similares. La clasificación jerárquica multivariada utilizó la distancia de Gower, y sobre esta distancia se aplicó el método de Ward como medida aglomerativa (Pla et al. 2012). De esta manera se obtiene un dendrograma y los valores de IV por especie en cada grupo.

Se calcularon los promedios de área basal total, de densidad total de individuos y de volumen total del fuste de los grupos o tipos de bosques, discriminados por clases diamétricas de G. sarmientoi y otras especies, siguiendo el cálculo:

$$
\theta=\frac{1}{\mathrm{~N}} \sum_{i=1}^{\mathrm{a}} \theta_{|c \mathrm{c}|}
$$

donde $\theta$ es el parámetro de estructura forestal promedio (e.g., área basal, densidad de individuos y volumen del fuste) del grupo o tipo de bosque, $\theta_{[\mathrm{CD}]}$ corresponde al parámetro dasométrico total (i.e., área basal total, densidad total de individuos y volumen del fuste) para la clase diamétrica (CD) de interés en cada una de las parcelas (n), $\mathrm{N}$ es el número total de parcelas de cada grupo o tipo de bosque obtenido.

\section{Relación estructura forestal, clima y suelos}

Con la base global de datos climáticos WorldClim 2.0 (Fick and Hijmans 2017) se extrajeron las variables de temperatura promedio anual $\left({ }^{\circ} \mathrm{C}\right)$ y precipitación promedio anual (mm/año) en el área de estudio (Figura 1B) para el período 1970-2000 (Fick and Hijmans 2017). La evapotranspiración potencial promedio anual (mm/año) fue obtenida a partir de datos ráster de alta resolución $\left(\sim 1 \mathrm{~km}^{2}\right)$ basados en la ecuación de evapotranspiración de FAO Penman Monteith (Trabucco and Zomer 2019). Se extrajeron los valores de pendiente del terreno (\%) utilizando un modelo de elevación digital generado a partir de imágenes satelitales SRTM (Shuttle Radar Topography Mission), con tamaño de píxel de 30x30 m (Farr et al. 2007). Se midió la profundidad del suelo principal entre 25-120 cm y se consideraron todos los gradientes de texturas del suelo clasificadas entre arena, limo y arcilla. Estas últimas variables edáficas fueron extraídas a partir del Mapa de Suelos de la República Argentina, con una escala 1: 500000, clasificadas de acuerdo con la Soil Taxonomy 1975 (INTA 1990). Todos los valores climáticos y edáficos fueron extraídos para cada parcela del inventario forestal dentro del área de estudio (Figura 1B).

Por medio de un modelo lineal generalizado y un modelo lineal general (MLG) se analizaron las variables de respuesta área basal total, densidad total de individuos, volumen total del fuste y altura media dominante, referidas sólo al palo santo por parcela y por grupo de bosque. Estas variables se modelaron en función de la temperatura promedio anual (TEMP), la precipitación promedio anual (PP), la evapotranspiración promedio anual (ETP), la pendiente del terreno (PEND), la profundidad del suelo (PROF) y la textura del suelo. De esta manera, cada MLG fue puesto a prueba a través de las siguientes ecuaciones:

$$
\begin{aligned}
& \mathrm{g}(\mathrm{Y})=\beta_{0}+\beta_{1} \mathrm{X}+\varepsilon \\
& \mathrm{g}(\mathrm{Y})=\beta_{0}+\beta_{1} \mathrm{X}+\beta_{2} \mathrm{Z}+\varepsilon
\end{aligned}
$$$$
\text { (Ecuación 4) }
$$

(Ecuación 5)

donde $\mathrm{Y}$ corresponde a las variables respuestas de estructura forestal del palo santo en las parcelas (i.e., área basal total, densidad total de individuos, etc.), X corresponde a cada una de las variables climáticas y edáficas (i.e., temperatura promedio, 
precipitación promedio, evapotranspiración, pendiente, profundidad y texturas del suelo) y Z corresponde al factor grupo o tipo de bosque con presencia de palo santo. $\beta_{0}$ y $\beta$ corresponden a los parámetros lineales del modelo, $\varepsilon$ corresponde a término de error del MLG, y la función $\mathrm{g}(\mathrm{Y})$ refiere a una función de enlace logaritmo natural según la familia de distribución teórica exponencial ajustada en cada MLG. Los modelos lineales generalizados se ajustaron con distribución Gamma (Dunn and Smyth 2018). Se analizaron relaciones lineales, cuadráticas o logarítmicas en el caso de variables explicativas continuas. La Ecuación 4 se puso a prueba para evaluar las relaciones de estructuras forestal del palo santo en todas las parcelas del área de estudio, mientras que la Ecuación 5 fue evaluada por grupo o tipos de bosques con palo santo obtenidos por clasificación multivariada.

\section{Modelo de biomasa de palo santo}

Se analizó el comportamiento de la biomasa total según el número de individuos de palo santo por hectárea, explorando cuáles grupos de bosques de palo santo logra mayores incrementos o pérdidas de biomasa. Esto permite determinar posibles cosechas o retenciones de árboles de palo santo considerando la biomasa producida. Para esto se utilizó un MLG, con la biomasa total leñosa como variable respuesta y la densidad de individuos como variable explicativa por el factor grupo de bosque de palo santo, evaluando relaciones lineales y no-lineales (Dunn and Smyth 2018). Todos los análisis fueron realizados con software libre $\mathrm{R}$ versión 3.6.0 (R Core Team 2019).

\section{Resultados}

\section{Estructura forestal de palo santo}

Los resultados del inventario correspondiente a todos los árboles mayores a $5 \mathrm{~cm}$ de DAP arrojaron 79 especies de árboles nativos. Las especies más abundantes fueron G. sarmientoi $(17.5 \%)$, S. triflora $(19.2 \%)$, A. quebracho-blanco $(11.6 \%)$, T. nodosa $(8.0 \%)$ y S. mistol $(7.0 \%)$. El rango de DAP para todos los individuos varió entre $5.0-115.0 \mathrm{~cm}$, con un promedio \pm desvío estándar de $15.5 \pm 10.1 \mathrm{~cm}$, y el rango de altura total fue 1.7-35.0 m, con un promedio \pm desvío estándar de $6.4 \pm 2.8 \mathrm{~m}$. Para todas las parcelas del inventario, la densidad total de individuos fluctuó entre 10.0-2668.0 individuos/ha (38.5 \pm 17.7 individuos/ha), el área basal total varió entre $0.7-30.9 \mathrm{~m}^{2} / \mathrm{ha}\left(11.9 \pm 4.6 \mathrm{~m}^{2} / \mathrm{ha}\right)$ y el volumen total del fuste varió de $1.5-67.4 \mathrm{~m}^{3} / \mathrm{ha}$ $\left(24.3 \pm 12.8 \mathrm{~m}^{3} / \mathrm{ha}\right)$.

Considerando sólo la especie G. sarmientoi, se registraron 2920 individuos, con un rango de DAP entre $5.0-81.5 \mathrm{~cm}(19.0 \pm 10.7 \mathrm{~cm})$ y un rango de altura total de $2.0-29.3 \mathrm{~m}(8.0 \pm 2.9 \mathrm{~m})$. El área basal total de palo santo varió entre 0.1-11.6 $\mathrm{m}^{2} / \mathrm{ha}\left(2.6 \pm 2.3 \mathrm{~m}^{2} / \mathrm{ha}\right)$. La densidad total de individuos de G. sarmientoi osciló entre 10.0-1340.0 individuos/ha (98.6 \pm 150.7 individuos/ha). El rango del volumen total del fuste de palo santo fue $0.1-31.8 \mathrm{~m}^{3} / \mathrm{ha}(5.7 \pm 5.7$ $\mathrm{m}^{3} / \mathrm{ha}$ ). La altura media dominante de palo santo mostró una variabilidad entre 5.0-22.1 $\mathrm{m}(11.7 \pm 2.7 \mathrm{~m})$. La regeneración total de palo santo mostró un máximo de 3200 individuos/ ha y un mínimo de 10.0 individuos/ha (482.6 \pm 562.3 individuos/ha).

\section{Clasificación de bosques con palo santo}

La clasificación jerárquica multivariada arrojó tres grupos bien definidos de bosques con palo santo (Figura 2A). Estos grupos se determinaron con un coeficiente aglomerativo del $93 \%$ para un valor de agrupamiento o corte del dendrograma en 0.26 (Figura 2A, línea de puntos). El grupo 1 quedó formado por 168 parcelas con la mayor participación de G. sarmientoi ( $I V=24.2 \%$ ) (Figura 2B). También dentro del grupo 1 se observó una gran participación de otras especies como A. quebracho-blanco (IV=17.3\%) y T. nodosa (IV=11.7\%). Los grupos 2 y 3 mostraron la menor participación de palo santo (IV $=15.2 \%$, $\mathrm{IV}=15.6 \%$, respectivamente). Sin embargo, el grupo 2 tuvo una menor riqueza de las restantes especies y buena participación de A. quebracho blanco (IV=16.5\%) (Figura 2B). Este último grupo se formó con 98 parcelas. Mientras tanto, el grupo 3 tuvo mayor participación de las restantes especies, como A. quebracho-blanco (IV=14.2\%), S. triflora $(\mathrm{IV}=11.3 \%)$, S. mistol $(\mathrm{IV}=8.1 \%)$, S. lorentzii (IV=7.1\%) y $T$. nodosa (IV=6.5\%), entre otras (Figura 2B). Este último grupo se formó con 216 parcelas.

La densidad total de palo santo fue significativamente mayor para el grupo 1, seguido por el grupo 3, y fue menor en el grupo 2 (Tabla 2). De la misma manera, la regeneración fue significativamente mayor para el grupo 1, seguido por el grupo 3, y fue menor en el grupo 2 (Tabla 2). La altura media dominante de palo santo fue significativamente menor para el grupo 1 , 


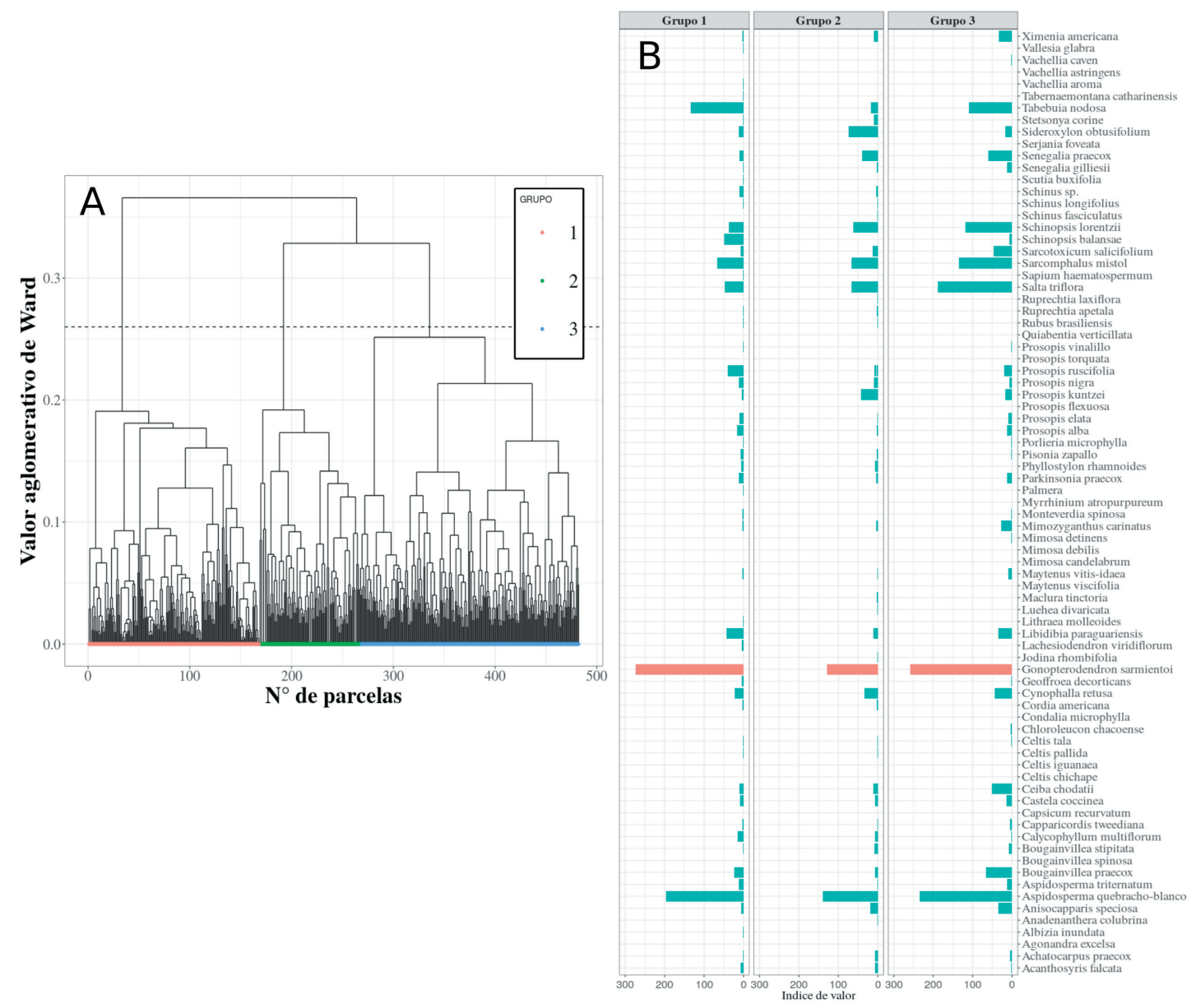

Figura 2. (A) Dendrograma de clasificación multivariada, en el que el grupo 1 (palosantal) se formó con 168 parcelas, el grupo 2 (bosque con baja presencia de palo santo) con 98 parcelas y el grupo 3 (bosque con alta presencia de palo santo) con 216 parcelas. (B) Índice de valor de todas las especies para los grupos de bosques obtenidos. En rojo se destacan los valores referidos al palo santo.

Figure 2. (A) Dendrogram from multivariate classification. Group 1 (palosantal) was formed with 168 plots; group 2 (forest with low presence of palo santo), with 98 plots and group 3 (forest with high presence of palo santo), with 216 plots. (B) Forest Value Index of all tree species in the classified palo santo groups.

Tabla 2. Valores promedio \pm desvío estándar de las variables de estructura forestal referidos a los grupos de bosques con palo santo. Entre paréntesis figura la cantidad de parcelas en cada grupo.

Table 2. Mean \pm standard deviation of forest stand attributes of palo santo groups. In brackets, the number of plots by groups is shown.

\begin{tabular}{lccc}
\hline Parámetro dasométrico & $\begin{array}{c}\text { Grupo 1 }(\mathrm{n}=168) \\
\text { palosantal }\end{array}$ & $\begin{array}{c}\text { Grupo 2 }(\mathrm{n}=98) \\
\text { bosques con baja } \\
\text { presencia }\end{array}$ & $\begin{array}{c}\text { Grupo 3 }(\mathrm{n}=216) \\
\text { bosques con alta } \\
\text { presencia }\end{array}$ \\
\hline Densidad total (individuos/ha) & $122.90 \pm 192.42^{\mathrm{a}}$ & $47.13 \pm 51.37^{\mathrm{b}}$ & $79.52 \pm 95.33^{\mathrm{ac}}$ \\
Regeneración (individuos $/ \mathrm{ha})$ & $683.07 \pm 740.84^{\mathrm{a}}$ & $163.15 \pm 152.20^{\mathrm{b}}$ & $428.12 \pm 324.51^{\mathrm{ac}}$ \\
Altura media dominante $(\mathrm{m})$ & $9.40 \pm 2.49^{\mathrm{a}}$ & $11.03 \pm 2.56^{\mathrm{b}}$ & $10.32 \pm 2.61^{\mathrm{bc}}$ \\
Área basal total $\left(\mathrm{m}^{2} / \mathrm{ha}\right)$ & $2.70 \pm 2.38^{\mathrm{a}}$ & $2.53 \pm 2.15^{\mathrm{a}}$ & $2.45 \pm 2.15^{\mathrm{a}}$ \\
Volumen total del fuste $\left(\mathrm{m}^{3} / \mathrm{ha}\right)$ & $5.39 \pm 4.92^{\mathrm{a}}$ & $7.35 \pm 6.88^{\mathrm{a}}$ & $5.62 \pm 5.41^{\mathrm{a}}$ \\
Biomasa total $(\mathrm{Mg} / \mathrm{ha})$ & $19.34 \pm 18.59^{\mathrm{a}}$ & $20.84 \pm 18.24^{\mathrm{a}}$ & $19.21 \pm 17.94^{\mathrm{a}}$
\end{tabular}

Letras diferentes indican diferencia significativa $(\mathrm{P}<0.05)$ con prueba de Kruskal-Wallis y comparaciones de Dunn. 
seguido por el grupo 3, y fue mayor en el grupo 2 (Tabla 2). Tanto el área basal total, el volumen total del fuste y la biomasa total no arrojaron diferencias significativas entre los grupos de bosques con palo santo (Tabla 2). El grupo 1 presentó la mayor densidad de individuos, área basal y volumen del fuste en las clases diamétricas inferiores de palo santo (Figura 3A, 3B, y 3C). El grupo 2 mostró la mayor área basal y volumen del fuste de palo santo en las clases diamétricas 30-49.9 cm (Figuras 3D, 3E y 3F). El grupo 3 tuvo mayor área basal y volumen del fuste entre las clases diamétricas 10-39.9 cm (Figuras 3G, 3H y 3I). Respecto a las otras especies, la densidad, el área basal y el volumen del fuste mantuvieron una distribución de J invertida a lo largo de las clases diamétricas en todos los grupos (Figura 3A a 3I). De esta manera, el grupo 1 se clasificó como palosantal, el grupo 2 como bosques con baja presencia de palo santo y el grupo 3 como bosques con alta presencia de palo santo (Figura 2B, Tabla 2).

\section{Relación estructura forestal, clima y suelos}

Para el total de parcelas recopiladas dentro del área de estudio se registraron rangos de temperatura media anual (TEMP, entre $21.8 \mathrm{y}$ $23.9^{\circ} \mathrm{C}$ ), precipitación media anual (PP, entre 627 y $1191 \mathrm{~mm} / \mathrm{año}$ ) y evapotranspiración media anual (ETP, de 1800 a 2000 mm/año). La pendiente del terreno (PEND) varió entre 1.7-9.2\%, representando terrenos de planicies extensas. A nivel de parcelas, los MLG arrojaron relaciones significativas de tipo lineal, logarítmicas y cuadráticas (Figura 4). La PP tuvo un efecto significativo negativo sobre el área basal total del palo santo (Figura 4A), la densidad total de individuos (Figura
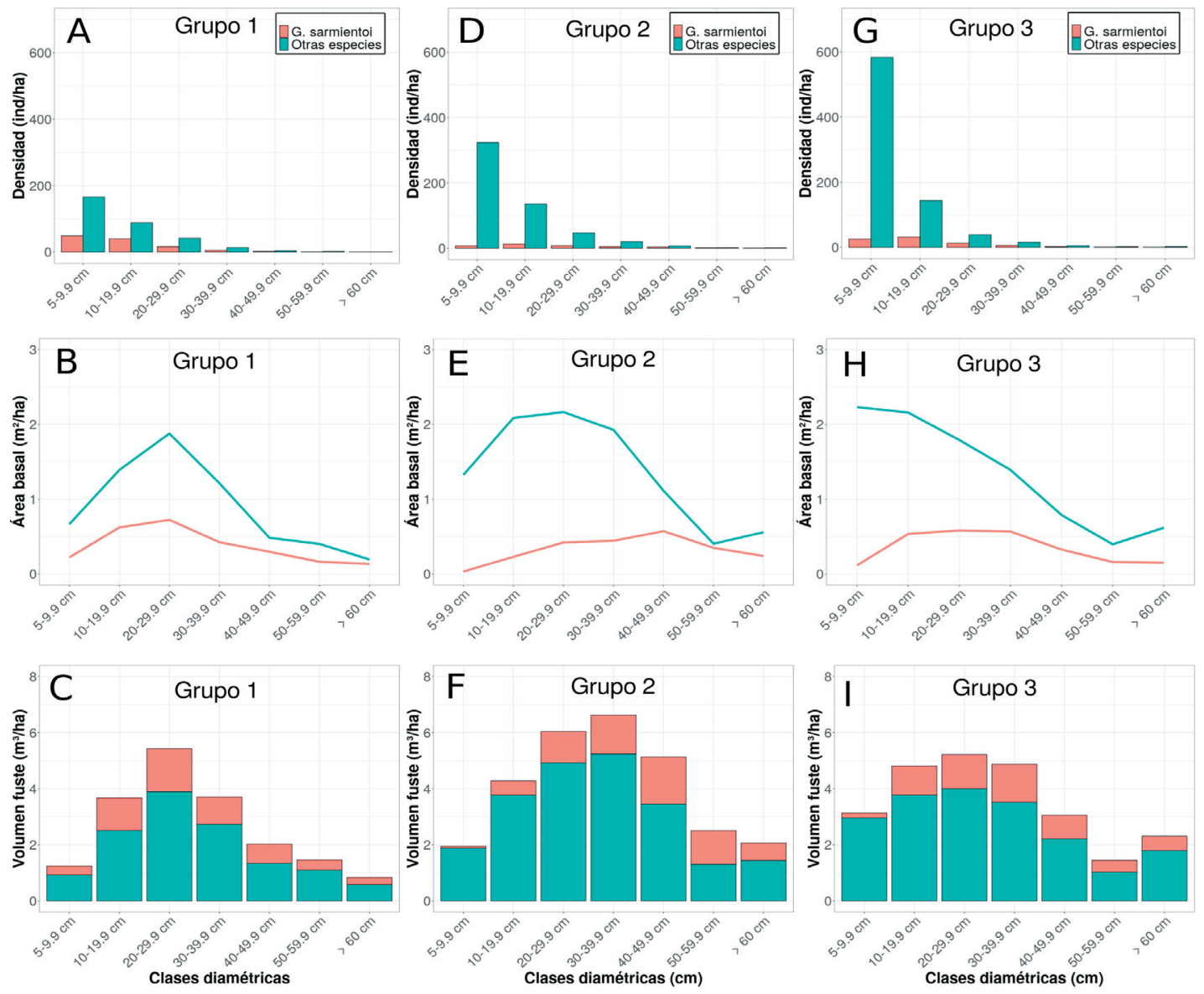

Figura 3. Densidad de individuos, área basal y volumen del fuste por clases diamétricas para G. sarmientoi y otras especies en el grupo 1 (palosantal) (A, B, C), en el grupo 2 (bosque con baja presencia de palo santo) (D, E, F) y en el grupo 3 (bosque con alta presencia de palo santo) $(\mathrm{G}, \mathrm{H}, \mathrm{I})$.

Figure 3. Density, basal area and volume by diametric classes for G. sarmientoi and other tree species in group 1 (palosantal) $(\mathrm{A}, \mathrm{B}, \mathrm{C})$, in group 2 (forest with low presence of palo santo) $(\mathrm{D}, \mathrm{E}, \mathrm{F})$ and in group 3 (forest with high presence of palo santo) $(\mathrm{G}, \mathrm{H}, \mathrm{I})$. 
4B), el volumen total del fuste (Figura 4E) y la altura media dominante (Figura 4F). Los valores mínimos de PP (i.e., 600-800 $\mathrm{mm} / \mathrm{año}$ ) se relacionan con mayores valores de éstos últimos parámetros dasométricos de palo santo. La ETP tuvo una relación ligeramente cuadrática con la densidad total de palo santo (Figura 4C), al igual que la TEMP sobre el volumen total del fuste (Figura 4D). A nivel regional, el régimen de precipitaciones, temperaturas y evapotranspiración de climas semiáridos muestran relación con el mayor desarrollo de las estructuras forestales del palo santo en todas las parcelas. No se encontraron relaciones significativas entre la estructura forestal del palo santo con la pendiente del terreno y la profundidad del suelo a nivel de parcela. La textura edáfica arcillosa mostró los menores valores de área basal total, densidad y volumen total del fuste para el palo santo (Figura 5A, 5B y 5C), mientras que las texturas arenosa y areno franca tuvieron un efecto positivo sobre éstos últimos parámetros dasométricos (Figura 5A, 5B, 5C). También, suelos franco arcillosos y franco arenosos mostraron mayor densidad de individuos de palo santo y menor densidad en suelos franco limosos respecto al promedio (Figura 5B). Los MLG de parámetros dasométricos totales de palo santo a nivel región (Ecuación 4) tuvieron menor bondad de ajuste residual, que osciló entre $0.9-9.4 \%$. Sin embargo, las relaciones mostraron una varianza homogénea y buena distribución de los valores residuales.

A nivel de grupos o de tipos de bosques con palo santo, la PP tuvo un efecto significativo negativo sólo sobre el área basal total del grupo
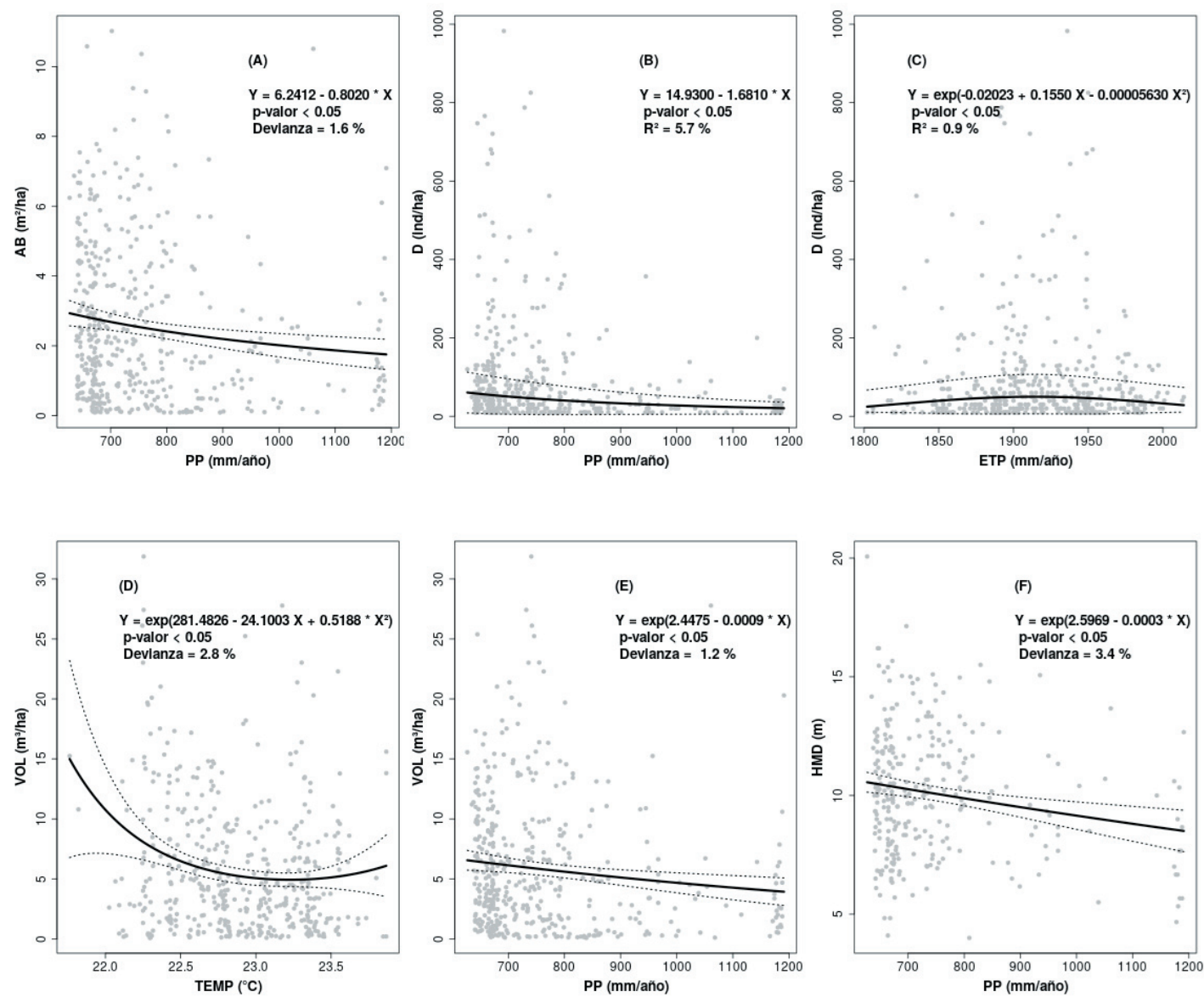

Figura 4. Relaciones entre parámetros dasométricos totales de palo santo y variables climáticas para todas las parcelas del inventario. A) Área basal total (AB) vs. PP (precipitación promedio anual). B) Densidad total de individuos (D) vs. PP. C) Densidad total de individuos (D) vs. ETP (evapotranspiración potencial). D) Volumen total del fuste (VOL) vs. TEMP (temperatura promedio anual). E) Volumen total del fuste vs. PP. F) Altura media dominante (HMD) vs. PP.

Figure 4. Relationships between total palo santo dasometric parameters and climatic variables for all inventory plots. A) Total basal area (AB) vs. PP (annual average precipitation). B) Total density of individuals (D) vs. PP. C) Total density (D) vs. ETP (potential evapotranspiration). D) Total volume (VOL) vs. TEMP (annual average temperature). E) Total volume (VOL) vs. PP. F) Mean dominant height (HMD) vs. PP. 

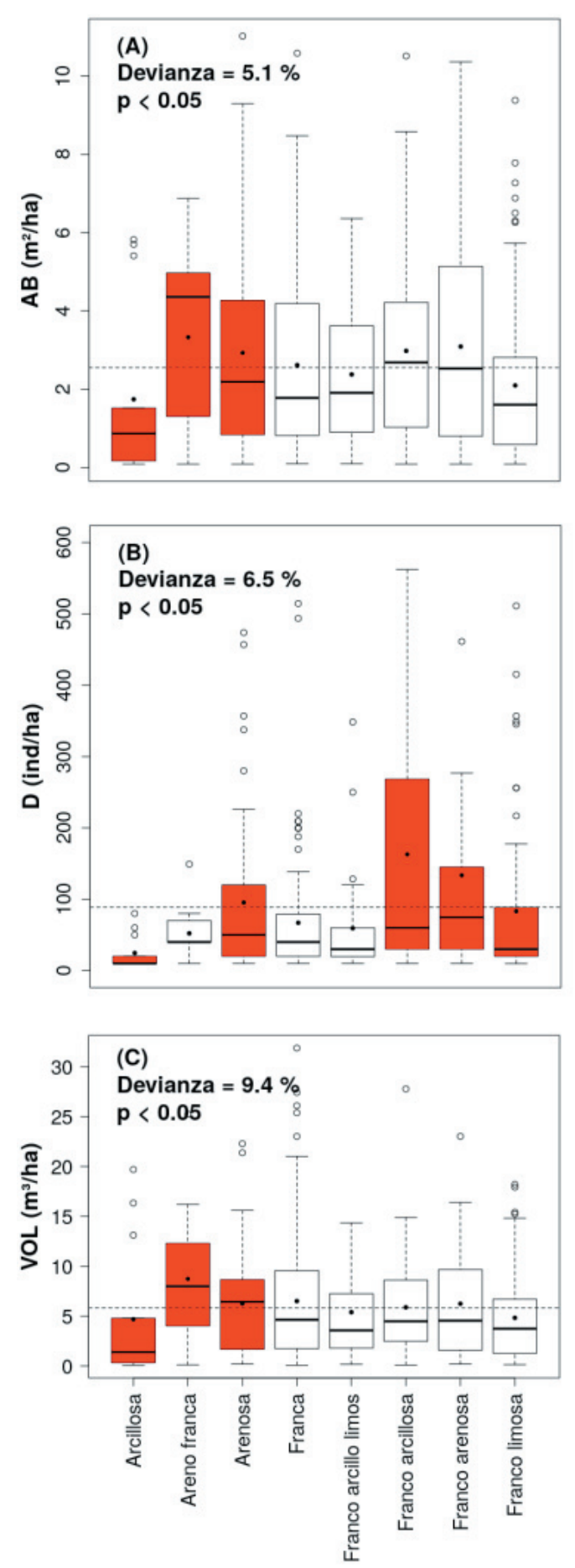

Figura 5. Área basal total (A), densidad total (B) y volumen total del fuste (C) de palo santo en todas las parcelas del inventario en relación con la diferentes texturas del suelo. En rojo, las texturas con efecto significativo $(\mathrm{P}<0.05)$ respecto al promedio general (línea de guiones). El punto oscuro indica el promedio de la textura del suelo.

Figure 5. Total basal area (A), total density of individuals (B), and total volume (c) of palo santo for all forest plots in relation to soil textures. Red boxes show a significant effect in relation to the general average (dashed line). Dark points indicate the average soil texture.
1 o palosantales (Tabla 3 ). En los grupos 1 y 2, la PP afectó de forma negativa la densidad total de individuos de palo santo (Tabla 2), mientras que valores intermedios de ETP (1900 $\mathrm{mm} / \mathrm{año}$ ) afectaron positivamente la densidad de individuos y valores extremos (1800 y 2000 $\mathrm{mm} / \mathrm{año}$ ) tuvieron un efecto negativo sobre esta variable (Tabla 3). El volumen total del grupo 1 disminuyó significativamente a medida que aumentó la TEMP (Tabla 3); de la misma manera, disminuyó el volumen del fuste a medida que aumentó la PP en los grupos 1 y 2 (Tabla 3 ). En este sentido, mayores valores de precipitaciones también tuvieron un efecto negativo sobre la altura media dominante de todos los grupos (Tabla 3). No se encontraron relaciones significativas entre la pendiente del terreno y la profundidad del suelo con los parámetros dasométricos de los grupos de palo santo (Tabla 3). La mayoría de las parcelas para todos los tipos de bosques con palo santo (grupos 1, 2 y 3) estuvieron en suelos de texturas francas $(31.7 \%, 33.3 \%$, $24.2 \%$, respectivamente) y franco limosas (24.5\%, 29.3\%, 32.2\%, respectivamente). La textura del suelo areno-franca mostró la menor área basal en promedio para el grupo 2 o bosques con baja presencia de palo santo (Tabla 4), mientras que la textura del suelo franca tuvo una mayor densidad de individuos para el grupo 3 o bosques con alta presencia de palo santo (Tabla 4). Suelos areno-francos mostraron menor volumen del fuste y altura media dominante en promedio en el grupo 2 (Tabla 4), y los suelos arenosos tuvieron menor altura media dominante en el grupo 3 (Tabla 4). Los MLG de los parámetros dasométricos por grupos o tipos de bosques de palo santo en función del clima y texturas de suelos (Ecuación 5) arrojaron una débil bondad de ajuste, que varió entre 1.2-15.2\%. Sin embargo, estos MLG tuvieron una varianza homogénea y buena distribución de residuales.

\section{Modelo de biomasa de palo santo}

La biomasa total leñosa del palo santo varió entre 0.2 a $92.6 \mathrm{Mg} / \mathrm{ha}$, con un promedio y desvío estándar de 19.7×18.3 Mg/ha, respectivamente. El modelo de biomasa fue significativo en función de la densidad de árboles de palo santo respecto a cada grupo (Figura 6) (bondad de ajuste=33\%, P<0.01). Este modelo tuvo un buen ajuste en homogeneidad y normalidad de valores residuales siguiendo una distribución teórica Gamma. La biomasa total del grupo 2 fue significativamente mayor que los grupos 1 y 3, dado que en estos últimos no hubo diferencias significativas (Figura 6). 
Tabla 3. Modelos lineales generales y generalizados con relaciones significativas $(\mathrm{P}<0.05)$ entre los parámetros dasométricos (variables de respuesta) de palosantal (grupo 1), bosque con baja presencia de palo santo (grupo 2), bosque con alta presencia de palo santo (grupo 3) y las variables climáticas (variables regresoras): TEMP (temperatura promedio anual), PP (precipitación promedio anual), ETP (evapotranspiración potencial), PEND (pendiente del terreno) y PROF (profundidad del suelo).

Table 3. General and generalized linear models with significant relationships $(\mathrm{P}<0.05)$ among forest attributes of palo santo groups (response variables) and climate variables (explanatory variables): TEMP (annual average temperature), PP (annual average precipitation), ETP (potential evapotranspiration), PEND (terrain slope) and PROF (soil deep).

\begin{tabular}{|c|c|c|c|c|c|c|}
\hline $\begin{array}{l}\text { Parámetro } \\
\text { dasométrico }\end{array}$ & $\begin{array}{l}\text { Tipo de } \\
\text { bosque }\end{array}$ & TEMP $\left({ }^{\circ} \mathrm{C}\right)$ & PP (mm/año) & ETP (mm/año) & $\begin{array}{l}\text { PEND } \\
(\%)\end{array}$ & $\begin{array}{l}\text { PROF } \\
(\mathrm{cm})\end{array}$ \\
\hline \multirow{3}{*}{$\begin{array}{l}\text { Área basal total } \\
\left(\mathrm{m}^{2} / \mathrm{ha}\right)\end{array}$} & Grupo 1 & - & $Y=\exp (1.771-0.0009 \mathrm{X})$ & - & - & - \\
\hline & Grupo 2 & - & - & - & - & - \\
\hline & Grupo 3 & - & - & - & - & - \\
\hline \multirow{3}{*}{$\begin{array}{l}\text { Densidad total } \\
\text { (individuos/ha) }\end{array}$} & Grupo 1 & - & $Y=\exp (5.5678-0.0020 X)$ & $Y=\exp \left(-201.90+0.2148 X-0.0005 X^{2}\right)$ & - & - \\
\hline & Grupo 2 & - & $Y=\exp (5.0399-0.0020 X)$ & $Y=\exp \left(-202.37+0.2148 X-0.0005 X^{2}\right)$ & - & - \\
\hline & Grupo 3 & - & - & - & - & - \\
\hline \multirow{3}{*}{$\begin{array}{l}\text { Volumen total } \\
\text { del fuste }\left(\mathrm{m}^{3} / \mathrm{ha}\right)\end{array}$} & Grupo 1 & $Y=23.3592-6.9137 X$ & $Y=\exp (2.3986-0.0009 X)$ & - & - & - \\
\hline & Grupo 2 & - & $Y=\exp (2.6912-0.0009 X)$ & - & - & - \\
\hline & Grupo 3 & - & - & - & - & - \\
\hline \multirow{3}{*}{$\begin{array}{l}\text { Altura media } \\
\text { dominante }(\mathrm{m})\end{array}$} & Grupo 1 & - & $\mathrm{Y}=\exp (2.5003-0.0003 \mathrm{X})$ & - & - & - \\
\hline & Grupo 2 & - & $Y=\exp (2.6417-0.0003 X)$ & - & - & - \\
\hline & Grupo 3 & - & $Y=\exp (2.5784-0.0003 X)$ & - & - & - \\
\hline
\end{tabular}

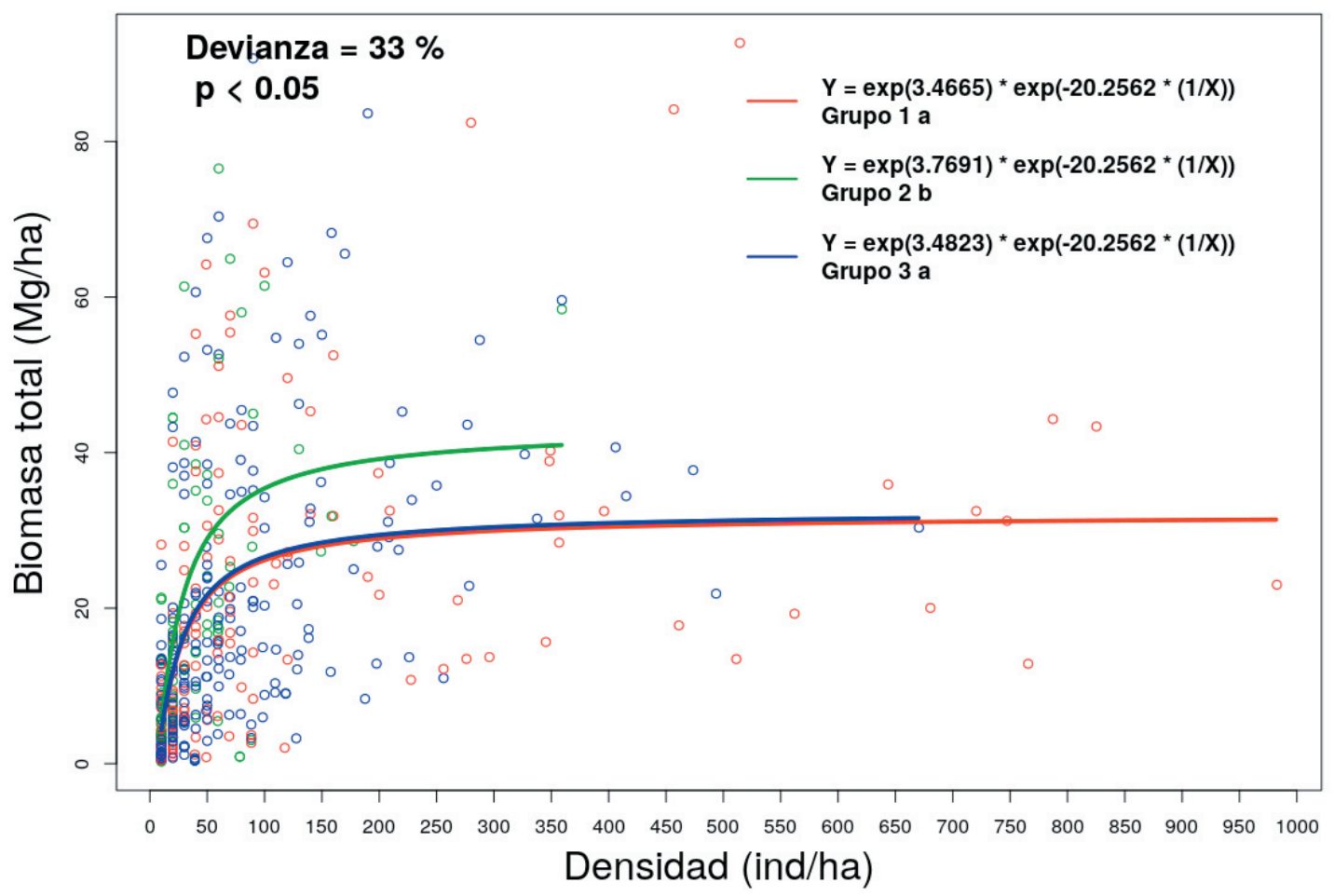

Figura 6. Biomasa total leñosa en función de la densidad de árboles de palo santo para el grupo 1 (palosantal), el grupo 2 (bosque con baja presencia de palo santo) y el grupo 3 (bosque con alta presencia de palo santo). Grupos con letras distintas son significativamente diferentes.

Figure 6. Total aboveground biomass as a function of tree density of palo santo for group 1 (palosantal), group 2 (forest with low presence of palo santo) and group 3 (forest with high presence of this species). Different letters indicate significant differences between groups. 


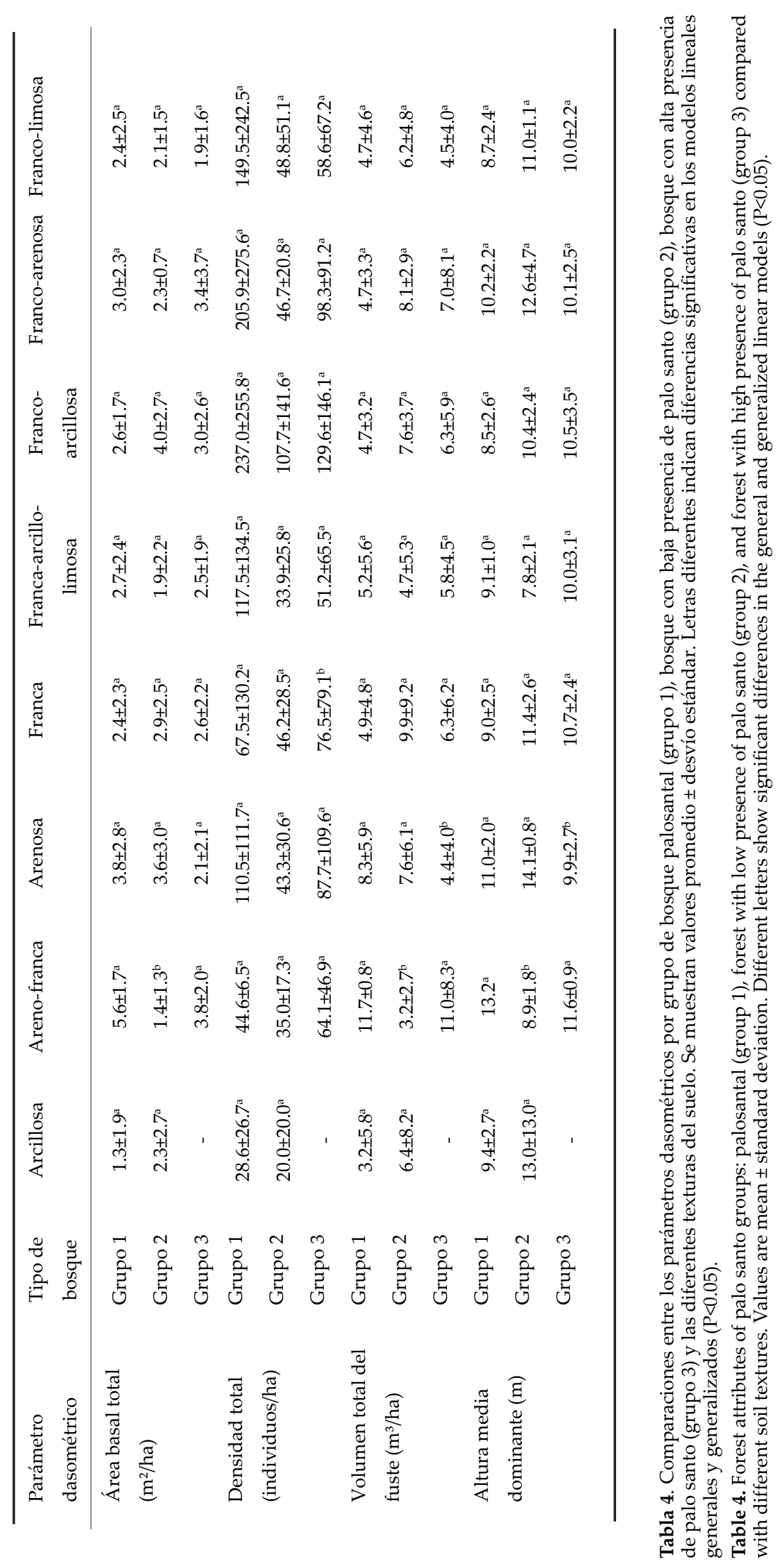


De esta manera, el tipo de bosque con baja presencia de palo santo (grupo 2) mostró una mayor pendiente, superando los 30 $\mathrm{Mg} / \mathrm{ha}$ de biomasa, con una densidad de 100 individuos/ha (Figura 6). Mientras tanto, el palosantal (grupo 1) y el tipo de bosque con alta presencia de palo santo (grupo 3) sólo superaron los $20 \mathrm{Mg} / \mathrm{ha}$, con 200 individuos/ ha (Figura 6). El palosantal y los bosques con alta presencia de palo santo (grupos 1 y 3) ofrecen la posibilidad de mayores cosechas de individuos por hectárea debido a la asíntota de biomasa total promedio entre densidades de 300 a 1000 individuos/ha (Figura 6). Mientras que los bosques con baja presencia (grupo 2) ofrecen una menor cosecha de individuos debido a su mayor pendiente de acumulación de biomasa. Sin embargo, para sostener mínimamente la acumulación de biomasa (i.e., $>20 \mathrm{Mg} / \mathrm{ha}$ ), se debería retener más de 30-40 individuos/ha de palo santo para el grupo 2 y más de 50-60 individuos/ha para los grupos 1 y 3 (Figura 6).

\section{Discusión}

\section{Clasificación de bosques con palo santo}

La clasificación de grupos de bosques con palo santo muestra que el índice IV forestal de las especies tiene un importante criterio de clasificación en las parcelas del área de estudio (Figura 2A). Esta clasificación en tres grupos destacó las diferentes participaciones de G. sarmientoi y las restantes especies. Un gradiente poblacional y de ambientes locales podría estar operando sobre esta clasificación de los grupos de bosques de palo santo. Por ejemplo, G. sarmientoi junto a A. quebrachoblanco, T. nodosa y $P$. ruscifolia dominaron en el grupo 1 (Figura 2B), lo cual indicaría sitios de palosantales o bosques casi puros de palo santo (Loto et al. 2018). Estos últimos se destacan por tener una mayor regeneración, densidad de árboles, área basal y volumen del fuste en las clases diamétricas $<29.9 \mathrm{~cm}$ del palo santo (Figura 3A, 3B y 3C). La estructura forestal de palosantal (grupo 1) coincide con descripciones para sitios frecuentemente inundables de suelos pobres y algo arcillosos (Morello and Adamoli 1974; Loto et al. 2018; Oyarzabal et al. 2018).

Para los bosques de baja presencia de palo santo (grupo 2), la mayoría de las especies tuvieron los valores más bajos de IV. En general, este grupo representaría bosques chaqueños con pocos árboles maduros y baja regeneración de G. sarmientoi (Tabla 2). En este grupo, la densidad de individuos, el área basal y el volumen del fuste estuvieron bien representadas en las clases diamétricas 30.0-49.9 $\mathrm{cm}$ para el palo santo (Figuras 3D, $3 \mathrm{E}$ y $3 \mathrm{~F}$ ). Estos bosques con menor presencia de palo santo también podrían indicar sitios degradados con disturbios recurrentes (Loto et al. 2018). Sin embargo, el conjunto de parcelas recopiladas en este trabajo no cuenta con información para el análisis de disturbios y aprovechamiento, lo que plantea la necesidad de avanzar en la toma de datos con registros de aprovechamientos para analizar el comportamiento de este tipo de bosques.

Los bosques con alta presencia de palo santo (grupo 3) se clasificaron por tener gran densidad de individuos en las clases diamétricas 10-39.9 cm (Figura 3G, 3H y 3I) y alta regeneración de palo santo (Tabla 2). Además, en este último grupo hubo una gran abundancia y riqueza de las restantes especies como A. quebracho-blanco, S. mistol, S. triflora y S. lorentzii (Figura 2B). Estos bosques parecen desarrollarse en sitios poco inundables, ampliamente distribuidos en el área de estudio ( $44 \%$ de las parcelas del inventario). Los rodales de bosques con alta presencia de palo santo serían lo más común para la región, en coincidencia con las descripciones de bosques chaqueños típicos del norte del Chaco Seco argentino (Cabrera 1976; Giménez and Moglia 2003; Loto et al. 2018).

\section{Relación estructura forestal, clima y suelos}

Los valores de estructura forestal del palo santo con las variables climáticas y edáficas mostraron relaciones significativas en el área de estudio. A partir de las relaciones climáticas y edáficas en todas las parcelas, la especie tendría un buen desempeño frente a las condiciones de aridez y lluvias moderadas de un clima semiárido (Figura 4). Esto se ve acompañado por los valores de precipitación promedio anual y evapotranspiración potencial del área de estudio, ya que valores de PP inferiores a $800 \mathrm{~mm} /$ año y ETP de $1900 \mathrm{~mm} / a$ ño se asocian con mayor área basal total (Figura 4A), densidad total de árboles (Figura 4B, 4C), volumen total del fuste (Figura 4E) y altura media dominante de palo santo (Figura 4F). Luego, estos parámetros dasométricos disminuyen a medida que aumenta la precipitación y la evapotranspiración potencial. El volumen total del fuste también mostró, en promedio, 
mayores valores por debajo de $22.5{ }^{\circ} \mathrm{C}$ de TEMP, y luego el volumen disminuyó con el aumento de las temperaturas (Figura 4D). Esto se relaciona con la covariación del mayores temperaturas y mayores precipitaciones en el norte del Chaco Seco (Cabrera 1976). Así, la hipótesis de especiación del palo santo en las regiones semiáridas-subhúmedas del sur de Sudamérica (Camps et al. 2018) estaría en concordancia con los resultados de este trabajo. Por lo tanto, a escala regional, los rodales de palo santo presentan una estructura forestal óptima frente a las condiciones climáticas semiáridas (Morello and Adamoli 1974). Los suelos de texturas areno franca, arenosa, franco-arcillosa y franco-arenosa mejoraron el área basal total, la densidad total de individuos y el volumen total del fuste de palo santo a nivel región (Figura 5). Esta especie desarrollaría grandes árboles sobre estos tipos de suelos (Viveros Cabaña 2005; Céspedes et al. 2018), mientras que en suelos arcillosos generalmente el área basal, la densidad de árboles y el volumen total del fuste son menores debido al escaso desarrollo estructural del suelo (de textura compacta y frecuentemente asociado a inundaciones) (Viveros Cabaña 2005). Nuestros resultados a nivel región indican que G. sarmientoi es una especie que se desarrolla en condiciones climáticas semiáridas y está bien adaptada a diversos tipos de suelos. Los modelos de relaciones entre estructura forestal de palo santo y las variables climáticas y edáficas mostraron bondades de ajuste débiles (0.9$9.4 \%$ ). Sin embargo, la disponibilidad de una base de datos climática y edáfica más precisa podría hacer más notorias dichas relaciones.

A nivel de grupos o tipos de bosques de palo santo, la precipitación promedio anual, la temperatura promedio anual y la evapotranspiración potencial también se relacionaron con la disminución del área basal total, la densidad total de árboles, el volumen total del fuste y la altura media dominante del palo santo (Tabla 3). Nuevamente, los regímenes climáticos semiáridos serían indicadores de mejores estructuras forestales en todos los grupos de bosques de palo santo, mientras que climas de mayores precipitaciones de regímenes subhúmedos tendrían menor desarrollo de rodales de palo santo (Tabla 3). Las texturas del suelo afectaron negativamente algunos grupos de bosques de palo santo como, por ejemplo, la textura del suelo areno-franca y arenosa, que mantuvo menor estructura forestal para los grupos 2 y 3 (Tabla 4). Estos tipos de suelos tienden a disgregarse y generalmente se asocian a erosión recurrente, lo que provoca un desarrollo menor de la estructura forestal de esta especie. Sin embargo, 5.3\% de las parcelas del grupo 2 y $13.5 \%$ de las parcelas del grupo 3 estuvieron en estos suelos con textura areno-franca y arenosa, respectivamente. Es posible que estos pocos sitios representen áreas puntuales cercanas a ríos, paleocauces, peladares y con degradación. También en el grupo 3 de bosques con alta presencia de palo santo se determinó una mayor densidad de individuos, en promedio, sobre texturas de suelo franca (Tabla 4). Esto es debido a una gran presencia de renovales e individuos juveniles en el grupo 3. Los suelos pobres y estacionalmente inundables han sido asociados a palosantales (Morello and Adamoli 1974), donde G. sarmientoi es la especie dominante en asociación con Tabebuia nodosa y Prosopis ruscifolia (Cabrera 1976; Loto et al. 2018). Aunque los suelos arcillosos y pobres en nutrientes han mostrado una menor estructura forestal (Figura 5), sólo las parcelas con palosantales y bosques con baja presencia de palo santo (grupos 1 y 2) estuvieron presentes y adaptados a suelos arcillosos (Tabla 4). En el presente trabajo, la resolución del muestreo de texturas de suelos (1:500000) resultaría limitada para encontrar mayores diferencias entre tipos de bosques. En este punto se plantea la necesidad disponer de muestreos edáficos más detallados que mejoren los resultados.

\section{Modelo de biomasa de palo santo}

El modelo de biomasa total tiene una proporcionalidad directa con el tamaño de los árboles (Chave et al. 2005). Esto se demostró en el tipo de bosque con baja presencia de palo santo (grupo 2) debido a la densidad de árboles con gran tamaño (Figura 6). En cambio, los grupos 1 y 3 acumularon menos biomasa debido a la presencia de pequeños árboles de palo santo, y en entre estos últimos grupos no hubo diferencias significativas (Figura 6). El palosantal (grupo 1) y el tipo de bosque con alta presencia de palo santo (grupo 3) ofrecen una mayor cantidad de individuos (entre 3001000 individuos/ha) (Figura 6) con menores tamaños para cosecha, sin mayores pérdidas de biomasa total (Figura 6), mientras que el tipo de bosque con baja presencia de palo santo (grupo 2) ofrece una menor cantidad de árboles de gran tamaño para cosecha (entre 150 a 350 individuos/ha) (Figura 6); esto se 
debió a un rápido incremento de biomasa total (mayor pendiente) con bajas densidades de individuos (Figura 6). Sin embargo, un exceso de cosechas en el grupo 2 provocaría mayores pérdidas de biomasa con respecto a los grupos 1 y 3 . De esta manera, la retención de 30-40 individuos/ha de palo santo en el tipo de bosques con baja presencia (grupo 2) y 5060 individuos/ha en palosantales y bosques de alta presencia (grupos 1 y 3) conservaría un mínimo de $20 \mathrm{Mg} / \mathrm{ha}$ de biomasa leñosa. Considerando estas diferencias en el modelo de biomasa, los grupos de bosques de palo santo ofrecen distintas posibilidades para el manejo y conservación del recurso considerando únicamente la densidad y el tamaño de sus árboles de palo santo.

\section{Implicancias para el manejo forestal}

A nivel regional, los tres grupos de bosques de palo santo pueden ser considerados para algunas líneas de planificación del manejo forestal. Cada grupo de bosque ofrece diferentes posibilidades forestales inherentes a sus estructuras boscosas y biomasa acumulada (Figura 3 y 6). Frecuentemente, la cosecha de árboles de palo santo en el área de estudio ocurre sobre los ejemplares de mejor calidad y diversos tamaños que van desde postes para alambrados hasta rollos industrializables (Waller 2009; Loto et al. 2018). Sin embargo, la amplia variedad de productos obtenidos con madera de palo santo hace difícil establecer un solo sistema de manejo silvícola sobre su área de distribución en la Argentina (provincias de Salta, Chaco y Formosa). El 'diámetro mínimo de corta' (DMC) continúa siendo el esquema de manejo más conocido en el norte argentino (Waller 2009). El DMC retiene árboles en pie con diámetros $<35 \mathrm{~cm}$ de DAP, extrayendo sólo individuos de gran tamaño, pero no da perspectivas acerca del comportamiento del conjunto de árboles remanentes frente a este aprovechamiento.

Para los palosantales (grupo 1) y bosques con alta presencia de palo santo (grupo 3), las prácticas de cosechas para postes y fustes pequeños a intermedios podrían realizarse no superando el 35\% de los individuos en estos sitios. Esto estaría sostenido por la biomasa acumulada (Figura 6) en grandes densidades de individuos de clases diamétricas inferiores (<29.9 cm DAP) (Figura 3A y 3G). Sin embargo, la práctica de DMC en estos tipos de bosques no sería factible debido a la baja densidad de árboles maduros. Ambos tipos de bosques ofrecerían una buena regeneración natural (Tabla 2) y es el aspecto más importante a tener en cuenta para un manejo forestal. Además, en los palosantales se ha observado el rebrote de tocones que logran alcanzar un buen tamaño en el corto plazo (Loto et al. 2018). Los bosques de los grupos 1 y 3 ofrecerían productos madereros de segunda magnitud como por ejemplo varillas, postes, y maderas para consumo de mercado local como cabos de herramientas, artesanías y tornería (CITES 2010).

En los bosques de baja presencia de palo santo (grupo 2), la densidad de individuos de clases diamétricas mayores ( $>30 \mathrm{~cm}$ DAP) (Figura 3D) permitiría manejos con cortas en ejemplares de gran tamaño y DMC. Sin embargo, a pesar de conseguir grandes cantidades de biomasa a bajas densidades de árboles, la intensidad de corta debería ser reduciday controlada.Además, la regeneración y la densidad promedio de individuos en este tipo de bosques es la menor (Tabla 2) y estaría controlada por la germinación a partir de pocos árboles semilleros. En este tipo de bosques se podrían aprovechar productos de primera magnitud, como rollos para industrias. El grupo 2 ofrecería una situación para el manejo forestal de grandes tamaños de árboles respetando los ciclos de sustentación del recurso.

La intensidad de corta en los diferentes grupos de bosques con palo santo continúa sujeta a la dinámica de crecimiento de la especie, la cual tiene un ciclo de corta superior a una década (Loto et al. 2018). Hasta el momento, la mejor información de valores de incremento periódico anual de palo santo son para árboles en pie de 20 a $60 \mathrm{~cm}$ de DAP (Loto et al. 2018). Con esta información se demostró que una intensidad de corta que supere el $80 \%$ de individuos cosechados compromete este recurso maderero a más de 50 años (Loto et al. 2018). De esta manera, para lograr una curva de crecimiento completa resulta necesario disponer de valores de incremento en árboles de palo santo con menor tamaño $(<20 \mathrm{~cm}$ DAP). Esto permitiría establecer de manera más precisa los tiempos y las intensidades de cosechas sin comprometer la disponibilidad del recurso.

Además, es necesario profundizar estudios sobre otras prácticas en la región, como la producción de mieles bajo la cobertura de estos bosques, la producción de carbón de palo santo, aceites esenciales, la artesanía de 
la madera y el uso de esta especie por parte de las comunidades aborígenes, entre otras (Waller 2009; Suárez 2014). Finalmente, las propuestas y planes de manejo de palo santo a nivel local o predial pueden no estar bien representados en nuestro inventario forestal de escala regional. Estos ambientes puntuales pueden incluir algunos sitios como áreas cercanas a ríos, terrenos bajos y asociaciones particulares de vegetación (Morello and Adamoli 1974), como así también áreas con regímenes de disturbios particulares debido a cortas sin manejo, ganadería y fuego. Las provincias involucradas en la distribución del palo santo en el norte de la Argentina (Salta, Formosa y Chaco) atienden diferentes objetivos, producciones y manejos dependientes de cada legislación provincial. Sin embargo, visibilizando un Plan Estratégico Nacional para el Manejo Sustentable del Palo Santo en la República Argentina se podrían considerar estos resultados para futuros estudios y propuestas de manejo para el uso y conservación de la especie.

Agradecimientos. Los autores agradecen al financiamiento del proyecto "Bases para la gestión sostenible de la especie Bulnesia sarmientoi 'palo santo' en la Región del Gran Chaco de Argentina" S-548 de la Secretaría CITES - "Apoyo a la Implementación del Plan Estratégico Nacional para Manejo Sustentable de Palo santo (Bulnesia sarmientoi)" PNUD ARG/19/004). Al Ministerio de Ambiente y Desarrollo Sustentable y Dirección Nacional de Bosques por el aporte de los inventarios forestales recientemente realizados. A colaboradores de inventarios forestales locales realizados en comunidades aborígenes, comunidades campesinas y particulares de las provincias de Salta, Chaco y Formosa. Finalmente agradecer a los revisores anónimos por los comentarios que mejoraron la claridad del presente trabajo.

\section{REFERENCIAS}

Barstow, M. 2018. Bulnesia sarmientoi: The IUCN Red List of Threatened Species 2018:e.T32028A68085692. http: /dx.doi.org/10.2305/IUCN.UK.2018-2.RLTS.T32028A68085692.en.

Cabrera, A. L. 1976. Enciclopedia Argentina de agricultura y jardinería. Regiones fitogeográficas Argentinas. Fascículo 1. Editorial

ACME, Buenos Aires, Argentina.

Camps, G. A., A. Cosacov, and A. N. Sérsic. 2021. Centre-periphery approaches based on geography, ecology and historical climate stability: what explains the variation in morphological traits of Bulnesia sarmientoi? Annals of Botany 127(7):943-955. https://doi.org/10.1093/aob/mcab034.

Camps, G. A., E. Martínez-Meyer, A. R. Verga, A. N. Sérsic, and A. Cosacov. 2018. Genetic and climatic approaches reveal effects of Pleistocene refugia and climatic stability in an old giant of the Neotropical Dry Forest. Biological Journal of the Linnean Society 125:401-420. https://doi.org/10.1093/biolinnean/bly115.

Céspedes, G., F. Mereles, and R. M. Navarro-Cerrillo. 2018. Método cualitativo para la determinación del estatus de conservación de Bulnesia sarmientoi (Zygophyllaceae) en Paraguay con fines de exportación. Collectanea Botanica 37: 006. https://doi.org/10.3989/collectbot.2018.v37.006.

Chave, J., C. Andalo, S. Brown, M. A. Cairns, J. Q. Chambers, D. Eamus, H. Fölster, F. Fromard, N. Higuchi, T. Kira, J.-P. Lescure, B. W. Nelson, H. Ogawa, H. Puig, B. Riéra, and T. Yamakura. 2005. Tree allometry and improved estimation of carbon stocks and balance in tropical forests. Oecologia 145:87-99. https://doi.org/10.1007/s00442-005-0100-x.

CITES. 2010. Examen de las propuestas de enmienda a los apéndices I y II. 15 Reunión de la Conferencia de las Partes. Doha, Qatar.

De Marzo, T., D. Pflugmacher, M. Baumann, E. F. Lambin, I. Gasparri, and T. Kuemmerle. 2021. Characterizing forest disturbances across the Argentine Dry Chaco based on Landsat time series. International Journal of Applied Earth Observation and Geoinformation 98:102310.https://doi.org/10.1016/j.jag.2021.102310.

Dunn, P. K., and G. K. Smyth. 2018. Generalized Linear Models With Examples in R. Springer New York, New York, USA. https://doi.org/10.1007/978-1-4419-0118-7.

Farr, T. G., P. A. Rosen, E. Caro, R. Crippen, R. Duren, et al. 2007. The Shuttle Radar Topography Mission. Reviews of Geophysics 45(2):1-33. https://doi.org/10.1029/2005RG000183.

Fick, S. E., and R. J. Hijmans. 2017. WorldClim 2: new 1-km spatial resolution climate surfaces for global land areas. International Journal of Climatology 37(12):4302-4315. https://doi.org/10.1002/joc.5086.

Giménez, A. M., and J. G. Moglia. 2003. Arboles del Chaco Argentino: guía para el reconocimiento dendrológico. Universidad Nacional de Santiago del Estero, Santiago del Estero, Argentina.

Gomez, C., S. Kees, and J. Skoko. 2013. Estructura, Sanidad y Composición Florística del Bosque del predio de la EEA Ing. Guillermo N. Juárez en la Provincia de Formosa-Argentina. Sáenz Peña, Chaco, Argentina.

INTA. 1990. Suelos de la República Argentina. Argentina.

Kershaw, J. A., M. J. Ducey, T. W. Beers, and B. Husch. 2017. Forest mensuration. Fifth edition. Wiley/Blackwell, Chichester, UK॰); Hoboken, NJ. https://doi.org/10.1002/9781118902028.

Lamprecht, H. 1990. Silvicultura en los trópicos: los ecosistemas forestales en los bosques tropicales y sus especies 
arbóreas, posibilidades y métodos para un aprovechamiento sostenido. GTZ. Eschborn, Germany.

Loto, D. E., I. Gasparri, M. Azcona, S. García, and C. Spagarino. 2018. Estructura y dinámica de bosques de palo santo en el Chaco Seco. Ecología Austral 28:064-073. https://doi.org/10.25260/EA.18.28.1.0.615.

MAyDS. 2020. Segundo Inventario Nacional de Bosques Nativos: informe Parque Chaqueño: primera revisión. Ministerio de Ambiente y Desarrollo Sostenible de la Nación, Buenos Aires. Argentina.

Mereles, F., and L. Pérez de Molas. 2008. Bulnesia sarmientoi Lorentz ex Griseb., (Zygophyllacea): estudio de base para su inclusión en el Apéndice II de la Convención CITES. Asunción, Paraguay.

Morello, J., and J. Adamoli. 1974. La vegetación de la República Argentina. Las grandes unidades de vegetación y ambiente del Chaco Argentino. Segunda parte: Vegetación y Ambiente de la provincia de Chaco. Secretaria de Estado de Agricultura y Ganadería de la Nación. Instituto Nacional de Tecnología Agropecuaria, Buenos Aires. Argentina.

Oyarzabal, M., J. Clavijo, L. Oakley, F. Biganzoli, P. Tognetti, I. Barberis, H. M. Maturo, R. Aragón, P. I. Campanello, D. Prado, M. Oesterheld, and R. J. C. León. 2018. Unidades de vegetación de la Argentina. Ecología Austral 28:040-063. https://doi.org/10.25260/EA.18.28.1.0.399.

Pla, L. E., F. Casanoves, and J. A. Di Rienzo. 2012. Quantifying functional biodiversity. Springer, Dordrecht@; New York. USA. https://doi.org/10.1007/978-94-007-2648-2.

Powell, P. A., A. S. Nanni, M. G. Názaro, D. Loto, R. Torres, and N. I. Gasparri. 2018. Characterization of forest carbon stocks at the landscape scale in the Argentine Dry Chaco. Forest Ecology and Management 424:21-27. hittps://doi.org) 10.1016/j.foreco.2018.04.033.

R Core Team. 2019. R: A language and environment for statistical computing. Vienna, Austria.

SAyDS. 2014. Inventario forestal en bosques con presencia de palo santo (Bulnesia sarmientoi) en la zona del parque chaqueño semi-árido. Provincias de Salta (Dpto. Rivadavia) y del Chaco (Dpto. Güemes). Informe final, Secretaria de Ambiente y Desarrollo Sustentable. Dirección de Bosques. Ministerio de Salud y Ambiente. Fundación ProYungas. Buenos Aires, Argentina.

Suárez, M. E. 2014. Etnobotánica wichí del bosque xerófito en el Chaco semiárido salteño / Wichi ethnobotany of the xerophytic forest in the Semiarid Chaco, Salta province, Argentina. Editorial Autores de Argentina. Buenos Aires, Argentina

Thren, M. 1993. Serie técnica forestal dasometría Apuntes de Clase. Proyecto UNSE/GTZ. Facultad de Ciencias Forestales. Universidad Nacional de Santiago del Estero. Santiago del Estero, Argentina.

Torres, R., N. I. Gasparri, P. G. Blendinger, and H. R. Grau. 2014. Land-use and land-cover effects on regional biodiversity distribution in a subtropical dry forest: a hierarchical integrative multi-taxa study. Regional Environmental Change 14:1549-1561. https://doi.org/10.1007/s10113-014-0604-1.

Trabucco, A., and R. Zomer. 2018. Global Aridity Index and Potential Evapotranspiration (ET0) Climate Database v2. Consortium for spatial information. Dar Es Salaam, Tanzania.

Viveros Cabaña, P. D. 2005. Gestión de recursos nativos para forestación, reforestación y enriquecimiento de bosque de palo santo (Bulnesia sarmientoi), en área de distribución de la especie. Fundación para el Desarrollo Sustentable del Chaco. United States Agency International Development. Paraguay.

Waller, T. 2009. Situación de la especie palo santo (Bulnesia sarmientoi Lorentz ex Griseb) en la provincia de Formosa: estudios de sitios de extracción en los departamentos Matacos y Bermejo. Fundación Biodiversidad Argentina. Formosa, Argentina. 